\title{
Uma releitura da obra de Elisabeth Kubler-Ross
}

\author{
A reappraisal of the works of Elisabeth Kubler-Ross
}

Selene Beviláqua Chaves Afonso ${ }^{1}$

Maria Cecília de Souza Minayo ${ }^{2}$

${ }^{1}$ Serviço de Psicologia Médica, Instituto Fernandes Figueira, Fiocruz. Av. Ruy Barbosa 716, Flamengo. 22.250-020 Rio de Janeiro RJ. selene.zero@gmail.com ${ }^{2}$ Claves, ENSP, Fundação Oswaldo Cruz.

\begin{abstract}
This article presents a reappraisal of part of the works of Elizabeth Kubler-Ross, one of the most quoted authors addressing the end of life process, mourning and dying. Her work has contributed to a clearer understanding of these issues by health professionals, families, religious and lay people who handle and/or experience mourning. She has also been the subject of controversy related to ethical issues and the scientific rigor of her work. The books analyzed in this article are: On death and dying (1969); Questions and answers on death and dying (1971); Living with death and dying (1981); On children and death (1983); On life after death (1991) and Life lessons (2000). Key words Terminally ill patient, Palliative care during the end of life process, Children
\end{abstract}

Resumo Este artigo apresenta uma releitura de parte da obra de Elizabeth Ross, uma das autoras mais citadas sobre a questão da terminalidade da vida, do luto e do morrer. Sua obra tem sido de grande contribuição tanto para os profissionais de saúde como para pais, mães, filhos, parentes, leigos e religiosos que vivenciam o luto. Também tem sido alvo de controvérsias relacionadas a questões éticas e quanto a seu rigor científico. Os livros aqui comentados são: On death and dying (Sobre A morte e o morrer, de 1969); Questions and answers on death and dying (Perguntas $e$ respostas sobre a morte e o morrer, de 1971); Living with death and dying (Vivendo com a morte e os moribundos, de 1981); On children and death (Sobre as crianças e a morte, de 1983); On life after death (Sobre a vida depois da morte, de 1991) e Life lessons (Lições de vida, de 2000).

Palavras-chave Doente terminal, Cuidados paliativos na terminalidade da vida, Criança 
Elisabeth Kubler-Ross, psiquiatra suíço-americana, uma entre trigêmeos, nascida com pouco mais de novecentos gramas, desde o início da vida sentiu que precisaria trabalhar duro para provar que merecia viver. Marcada na adolescência pelos horrores da Segunda Guerra, prometeu - e cumpriu - trabalhar na Polônia e na Rússia, ajudando nos primeiros socorros aos necessitados. Aí começava seu interesse pela morte e o morrer.

Ela viu de perto os campos de concentração, os crematórios, os vagões de milhares de sapatinhos de bebês e de cabelos de vítimas do holocausto que serviriam de enchimento para travesseiros na Alemanha. Depois disso, nunca mais foi a mesma. Mais que isso, percebeu a desumanidade do ser humano e o potencial de cada indivíduo para, segundo suas palavras, se tornar um monstro nazista ou uma Madre Teresa de Calcutá. Considerava que todos nós temos que tomar conhecimento desses aspectos internos, bons e maus.

Kubler-Ross planejava trabalhar na Índia, mas foi demovida de seu plano original por terse casado com um americano que a levou para residir em Nova Iorque, último lugar em sua lista de preferências. Lá, insatisfeita e infeliz, identificou-se com a solidão desesperada dos pacientes que atendia em um hospital de emergências. Diante de sua presença e disponibilidade, eles começavam a falar e a compartilhar seus sentimentos e histórias. Ela tinha dificuldades em compreender o inglês que eles falavam, mas - e ainda que soubesse pouco de psiquiatria - entendeu a linguagem da alma daquelas pessoas. Para Kubler-Ross, aquelas vivências não foram mera coincidência e prenunciavam o trabalho que viria a fazer mais tarde em sua carreira.

Em 1969, publicou o livro intitulado On death and dying ${ }^{1}$ o primeiro de uma série que iria projetá-la pelo mundo como especialista num assunto tabu para as sociedades ocidentais. Traduzido para trinta línguas, sua obra foi além da descrição dos cinco estágios (negação, raiva, barganha, depressão e aceitação) pelos quais passam os pacientes diante de uma doença fatal ou que potencialmente ameace a vida. Em seus estudos de caso, dissecou situações relacionais entre a equipe, os pacientes, seus familiares e entre os próprios profissionais. A autora considerava que o conhecimento teórico era importante, mas que ele de nada valia se não se trabalhasse com o coração e a alma.

Seu livro Questions and answers on death and dying ${ }^{2}$, publicado em 1974, contém exemplos de situações vividas em sua atividade na clínica. Compila as perguntas mais frequentes respondidas por ela nos cinco anos seguintes ao lança- mento do primeiro livro, durante os cerca de setecentos grupos de trabalho, seminários e congressos que ministrou.

Nesse livro, Kubler-Ross aborda assuntos importantes como a interdisciplinaridade, os aspectos comunicacionais envolvidos na transmissão de notícias difíceis, o respeito à autonomia dos pacientes e a importância da família como parte da equipe em coparticipação para a construção de projetos terapêuticos singulares, entre outros. E ainda que não utilize qualquer desses termos, ela foi além da teoria, mostrando, com os relatos de suas vivências na clínica, o âmago dinâmico de cada um desses conceitos.

Em Living with death and dying ${ }^{3}$ de 1981, pela via dos exemplos da prática clínica, Kubler-Ross repete o formato de livros anteriores, mostrando os entraves e as soluções para a melhor abordagem junto a essas pessoas. O livro traz uma reflexão não só sobre pacientes terminais, mas sobre adultos, crianças saudáveis e seus familiares em outras situações críticas, tais como diante da perda inesperada dos entes queridos, por desaparecimento, acidente, assassinato ou suicídio.

Naquele final de século XX, a autora já discutia a transição do modelo de assistência em saúde estritamente hospitalar e biomédico para o modelo domiciliar ou de hospices. Reforçava a importância do tratamento holístico e discutia a relutância das equipes em administrar todos os recursos possíveis para aliviar as insuportáveis dores físicas e emocionais dos doentes. Dizia que a regra de ouro nesse novo modelo de atendimento era levar em conta a opinião dos pacientes sem julgá-los, mas ajudando-os a fazer suas escolhas. Ressaltava também que os membros da família precisam ser tão cuidados e orientados quanto o próprio paciente, para que se evite seu adoecimento emocional ao longo de todo o processo, do diagnóstico ao tratamento e no evento final.

Em sua obra, a autora não sistematiza seu conhecimento nem propõem fórmulas ou protocolos: o que ela faz é uma alusão à necessidade de preparo dos profissionais para lidar com essas circunstâncias, sem, no entanto, explicitar como prepará-los - provavelmente (se depreende) utilizando seu modelo de seminários, congressos e mesmo fitas e livros publicados. Tudo indica que, pela maneira com que lidava com a linguagem simbólica (especialmente no caso dos desenhos de crianças) e pela forma como tinha acesso ao inconsciente dessas pessoas, possa ter havido uma formação em psicanálise clássica ampliando, assim, sua visão do mundo emocional para além das teorias da psiquiatria. 
Nesse último livro, o capítulo escrito pela mãe de um paciente já alerta para a importância da simetria nas relações com a equipe, especialmente nos casos mais graves e com reinternações prolongadas, quando a exposição dos diversos atores é ainda maior. Percebe-se que, naquele tempo, Kubler-Ross colocava ênfase no que hoje, segundo a humanização em saúde, chamaríamos de projeto terapêutico singular e de clínica ampliada.

Em 1983, a autora dedica On children and death ${ }^{4}$ aos casos de crianças, no qual aborda as mudanças das sociedades ocidentais diante do nascimento de um novo membro da família. O que antes era um acontecimento compartilhado pela comunidade agora é vivido como uma interrupção dos planos dos pais. Do ponto de vista de Kluber-Ross, o parto foi medicalizado e, no fundo, ela aponta para a diminuição do contato entre os seres humanos, sobretudo quando as situações críticas da vida e da morte não são discutidas e elaboradas pelos que as vivenciam. Novamente utilizando como exemplos os casos que acompanhou e depoimentos pessoais - prestados em seus seminários ou mesmo em cartas que recebia -, a autora discorre sobre o adoecimento e os vários tipos de morte em crianças e adolescentes: das resultantes de doenças graves às inesperadas, e suas respectivas repercussões sobre as famílias.

Kubler-Ross abordava os pequenos por meio de desenhos que eles produziam durante os contatos com ela, e os interpretava como sonhos, numa alusão não explícita à provável influência dos estudos de Freud sobre o inconsciente e a interpretação dos sonhos. Usando uma linguagem simbólica, metafórica, Kubler-Ross respondia às perguntas das crianças à medida que elas iam se apercebendo de suas dramáticas realidades. A autora considerava que as crianças tinham mais clareza quanto ao seu estado do que se supunha e, portanto, estavam expostas também a uma dor e a um sofrimento maiores pelo fato de não poderem partilhar suas dúvidas, angústias e pensamentos com outras pessoas.

Nesse livro ela começa a revelar sua interpretação espiritualizada da morte e do morrer. É na conversa com as crianças - que, para a autora, precisam ser respeitadas como pessoas e têm o direito de conhecer sua condição por meio de informação honesta e aberta - que Ross começa a usar a metáfora do casulo e da borboleta.

Para ela, o corpo físico é a morada temporária da alma ou entidade que se liberta, como uma borboleta do casulo, para habitar uma dimensão atemporal, na qual não há dor nem sofri- mento; onde só há beleza, prazer e plenitude; onde a pessoa é recebida por um ente querido que já tenha feito o que ela chamava de transição, e onde nunca se está só. Essas ideias provocaram reações da comunidade científica, que considerava estar Kubler-Ross se afastando dos rigores metodológicos acadêmicos. A autora também aborda as consequências trágicas do luto mal elaborado dos pais e irmãos e a necessidade de tratálos por meio da escuta acurada e de orientação familiar para prevenir o adoecimento emocional, ajudando-os a superar a perda. No mesmo livro, há um capítulo com várias cartas e depoimentos de pais narrando suas lutas internas para compreender a morte dos filhos, para dar destino a seus sentimentos e continuar a viver.

Quando a autora escreve sobre os profissionais, suas vicissitudes, erros e acertos, oferecenos uma detalhada descrição do que hoje chamamos e esperamos que seja a reflexão em busca do atendimento humanizado em saúde.

On life after death ${ }^{5}$, de 1991, foi escrito na vigência das sequelas dos acidentes vasculares cerebrais sofridos pela autora. Naquele momento, ela se encontrava em uma cadeira de rodas, fisicamente dependente para realizar várias atividades diárias. Na abertura do livro ela endereça um ácido recado a seus detratores: ao invés de tentar convencê-los quanto à existência de vida após a morte, Kubler-Ross escreve que provavelmente estará presente na outra vida no momento em que eles irão constatar, pessoalmente, as convicções dela sobre o além.

Os estudos da autora sobre as experiências de quase morte fortaleceram sua crença numa instância superior e etérea, descrita por pessoas que estiveram clinicamente em estado crítico, assunto estudado até hoje. E, em razão dessa abordagem, Kubler-Ross foi questionada pela comunidade científica. Contra o argumento - que então prevalecia - de que essa experiência se devia à falta de aporte de oxigênio ao cérebro, causando ilusões preenchidas por desejos do paciente, ela citava os casos de pessoas cegas que durante o estado de quase morte puderam ver e, posteriormente, descrever os profissionais que haviam atuado em seu socorro. Sofrendo as pressões da comunidade científica e na iminência de abandonar a coordenação de seus famosos seminários, ela própria diz ter vivido o encontro com uma de suas pacientes, morta dez anos antes, que lhe pediu para não encerrar a atividade naquele momento.

Além dessa, a autora descreve outra experiência pessoal naquilo que chamava de consciência cósmica, citando haver caminhado por um vale 
sem tocar os pés no chão. Saindo desse estado mental lhe vieram à mente as palavras Shanti Nilaya, que - mais tarde veio a saber - significavam "última morada da paz". A expressão tornou-se depois o nome da instituição fundada por ela na Califórnia para cuidar de pacientes terminais e das vítimas da então novíssima e pouco conhecida epidemia de Aids.

Life lessons ${ }^{6}$, de 2000, escrito em parceria com Davi Kessler - também especialista no tema da morte e do morrer -, é seu primeiro livro sobre a vida e o viver. Das experiências com os pacientes e familiares ela tira lições sobre autenticidade, amor, relações pessoais, perda, força, tempo, medo, raiva, lazer, paciência, rendição, perdão e felicidade. Os autores mantêm a fórmula dos livros anteriores de Ross, repletos de exemplos de situações vividas por pessoas diante de uma perda ou de outros acontecimentos trágicos. Kubler-Ross conclui que, ao estudar a morte, ela aprendeu mais sobre a vida e seus mistérios.

A autora foi acusada pela comunidade científica de se ter autopromovido por meios pouco éticos, acusação que recai no fato de apenas na bibliografia ela ter citado os profissionais pioneiros nesse campo que já vinham trabalhando e publicando estudos sobre as mudanças necessárias no tratamento de pacientes terminais. Com isso, segundo seus críticos, a autora fez com que leitores apressados e menos criteriosos atribuíssem a ela todos os méritos sobre o assunto. Mesmo os cinco estágios experimentados por doentes diante da morte teriam sido uma apropriação de trabalhos de Robertson e Bolby ${ }^{7}$ sobre a reação de crianças afastadas de suas mães. Os críticos de Kubler-Ross também referem seu isolamento e dificuldades em trabalhar com os demais profissionais que vinham lutando pela melhoria no atendimento e cuidado dos pacientes terminais ${ }^{8}$.

Para seus defensores, debater os detalhes e a validade de suas teses ou seu flerte com a espiritualidade é perder de vista o centro do seu trabalho. Com um único livro e uma vigorosa campanha proselitista, Kubler-Ross permitiu o debate mais aberto sobre nosso maior medo e única certeza: a morte?.

Se há um valor incontestável em seus livros é o de colocar em relevo a subjetividade das pessoas, lidando corajosamente com ela. Não há teorias, estatísticas, esquemas, protocolos ou receitas de como lidar com a dor da perda, embora a autora admita a necessidade de haver um preparo dos profissionais para que eles possam atuar em tal função.

O que há são tocantes histórias de sofrimento e superação, de compartilhamento e amadurecimento sobre os quais ela trabalha, lançando luz sobre a prática e tornando os debates sobre os assuntos sobre a morte e o morrer tangíveis para profissionais e leigos. Para Elisabeth $\mathrm{Ku}-$ bler-Ross, essas experiências são, sobretudo, oportunidades de crescimento pessoal.

\section{Colaboradores}

SBC Afonso e MCS Minayo participaram igualmente da elaboração do artigo.

\section{Referências}

1. Kubler-Ross E. On death and dying. New York: Scribner; 1969.

2. Kubler-Ross E. Questions and answers on death and dying. New York: Touchstone; 1971.

3. Kubler-Ross E. Living with death and dying. New York: Touchstone; 1981.

4. Kubler-Ross E. On children and death. New York: Touchstone; 1983.

5. Kubler-Ross E. On life and death. Celestial Arts. New York: Touchstone; 1991.

6. Kubler-Ross E, Kessler D. Life lessons. New York: Scribner; 2000.

7. Robertson J, Bowlby J. Responses of young children to separation from their mothers. II Observations of the sequence of response of children aged 18 to 24 months during the course of separation. Courrier du Centre International de l'Enfance 1952; 3:131-142.

8. Parkes CM. Elisabeth Kubler-Ross, On death and dying: a reapprasail. Mortality 2013; 18(1):94-97.

9. Black and White Photograph [obituary]. Time 2004; 164(10):20.

Artigo apresentado em 30/04/2013

Aprovado em 22/05/2013

Versão final apresentada em 10/06/2013 